DOI: 10.2507/29th.daaam.proceedings.087

\title{
LOAD ANALYSIS OF CRANKSHAFT OF Two-Point Crank Press
}

\author{
Pavel Hamrle \& Jan Hlaváč
}
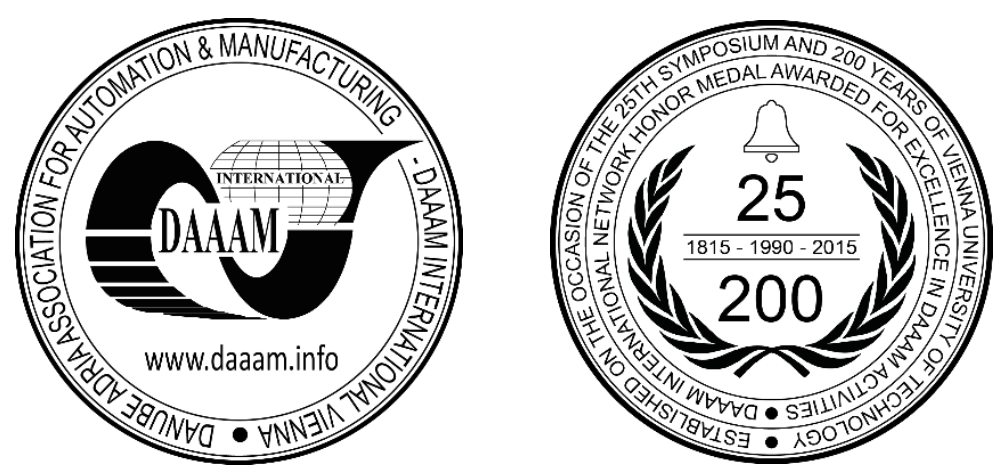

This Publication has to be referred as: Hamrle, P[avel] \& Hlavac, J[an] (2018). Load Analysis of Crankshaft of TwoPoint Crank Press, Proceedings of the 29th DAAAM International Symposium, pp.0601-0608, B. Katalinic (Ed.), Published by DAAAM International, ISBN 978-3-902734-20-4, ISSN 1726-9679, Vienna, Austria DOI: $10.2507 / 29$ th.daaam.proceedings.087

\begin{abstract}
Wide workspace is a common requirement for modern crank forging presses. As the working width increases, the crank shaft length is also increasing. The longer shaft is more stressed by the bending moment. From a certain length of the shaft, the one-point crank mechanism is replaced by a two point, which leads to the possibility of creating a middle support bearing. Although the central support bearing reduces the crank shaft stress, it adversely affects the press stand. It should not be forgotten that the stress of the shaft is also dependent on the position of the load force whether it is cantered or offcentre. The paper focuses on the durability analysis of the crank shaft with the two-point press with the central support bearing, using the solid-body theory and finite element method.
\end{abstract}

Keywords: Forging press; crank shaft; stress analysis; simple beam; FEM.

\section{Introduction}

\subsection{Background}

There is an attempt to replace the man with an automated machine even in the close die forging industry. In automated production, productivity is higher and quality is stable. The requirements for increased productivity in the forging process are shown by expanding the workspace. The reason for the enlargement of the press space are in particular: the need for more space for forgings, but also efforts to place as many of the forging operations per machine as possible. [1] The ideal machine must be able to upset, pre-forge, forge, calibrate and trim if it is necessary. Previously, all these forging operations were divided into several machines. [2]

\subsection{Problem definition}

The wider workspace brings greater load to the crossbar and eccentric shafts even at the same nominal force. The reason is that the bending moment of these components increases as the workspace increases. Their dimensioning is complicated due to the requirements for the nominal force of the press acting in any working position. 
Older forging machines designed for human service are often designed for three stage operations with the requirement to place the operation with the greatest force into the middle position. In automated procedures, a gradual sequence of operations from one side to the other is usually preferred. It is common that the operation with the highest force is in the extreme position, this puts increased demands on machine construction.

Another approach how to use a wide press with multiple position is to use all positions for simultaneous operations. The parallel used operations must not exceed press nominal force. It is modern to prepare very close forming forces for every position. [2]

Enlarged presses are often designed as two-point systems. The two-point solution provides the possibility of use of a middle bearing. The middle bearing enables significantly reduced bending stress on the eccentric shaft, but its use raises many other questions. How is the middle bearing loaded, or what is the system behavior when the load is off-center. The middle bearing, located in the center of the upper crossbar, can't be considered as a fixed point, unlike the outer bearings, because the upper crossbar also bents due to the load. Upon deflection of the upper crossbar there is a clamping of the stands, which complicates ram guidance. Furthermore, with the increasing load on the middle bearing, there is a problem with its load capacity.

\subsection{Used approaches}

The aim of this work is to develop and program the beam model simulation. The simulation of the beam model is simple, easy to use and can be easily used to verify a number of dimensional and load variants. The calculation is compiled in MS Excel. A virtual FEM simulation is used in a common press design process. This simulation describes the actual state of the system, but it is relatively time and resources demanding. Therefore, it is inappropriate for more variants.

\subsection{Modern forging press with wider workspace}

A standard forging machine of standard design (Fig. 1. left) with a nominal force of $25 \mathrm{MN}$ has a work table about $1.5 \mathrm{~m}$ wide. The eccentric shaft is mounted in two bearings in the outer position. The crank mechanism is one-point. The press is typically designed for three jobs. [3], [4]
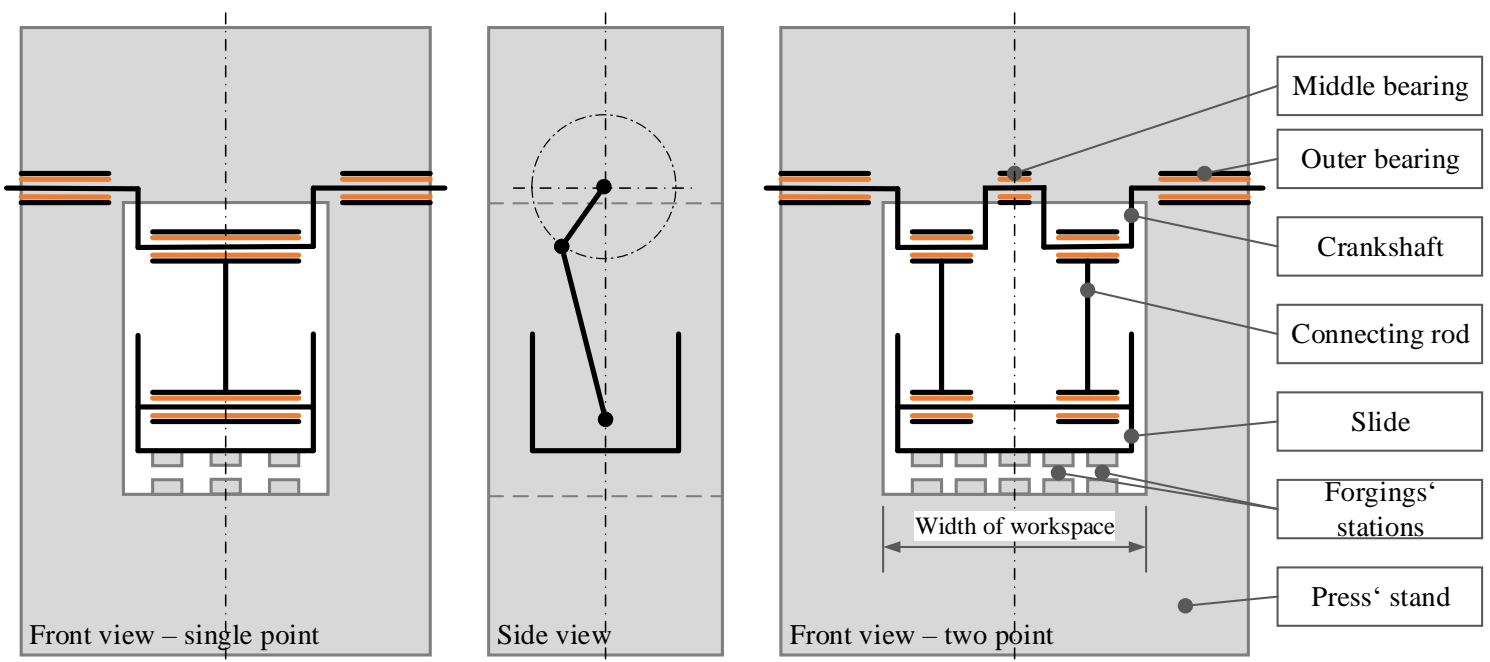

Fig. 1. Schematic representation of the crank press (left: single point, classical design, right: two point, modern design)

The modern forging machine (Fig. 1. right) with the same nominal force of $25 \mathrm{MN}$ can have a work table up to $2.5 \mathrm{~m}$ wide. The crank mechanism is usually two-point. If the eccentric "left to right" shaft is used, a middle bearing is also used. There are more working positions, typically five or six, and the nominal force of the press can be reached in any one of them. For the purpose of this study, only the shaft mounted into the press stand from left to right is considered.

\section{Crankshaft and its load}

The forging press crankshaft is an extremely strained component. The impact load is typical here. Since both high strength and sufficient toughness are required, it is typically made of Ni-Cr steel alloy (e.g., $35 \mathrm{NiCr} 6$ ). Semi-finished product for shaft production is forged piece. It is a relatively large part weighing in units to tens of tons. Due to the impact load of the shaft, sliding plain bearings (bronze sliding pans) are used. The load capacity of these bearings is relatively limited and is directly dependent on the projection area, which is given by the diameter of the shaft and the length of the plain bearing slide pan. There is an uneven load problem in the case of a bending moment transmission in the plain bearing. For the purposes of this study, linear (triangle) loads are considered for the outer bearings (Fig. 2.). 


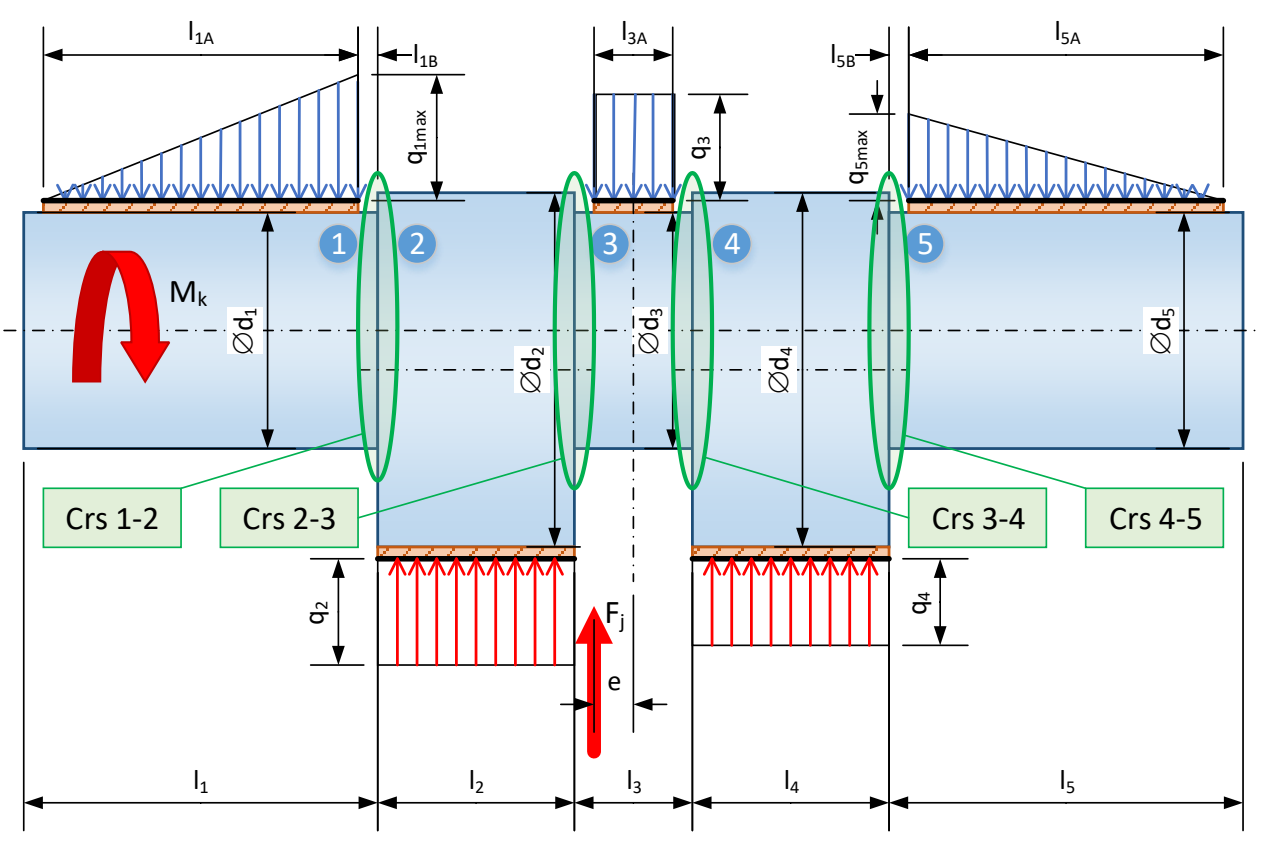

Fig. 2. Schematic representation of two point crankshaft and its load (sliding bearing with expected bearing pressure distribution)

\subsection{Simple beam model of the crankshaft}

The crankshaft can be considered, for simplicity, as a single beam on three supports. [5] For the purposes of subsequent strength checks, partial cylindrical volumes 1-5 (Fig. 2) are indicated. The stress is subtracted for cross-sections at the points between partial volumes. Its strain is quite complex and consists of bending, shearing and torsion. The nominal force is evenly distributed between the first and the second crank mechanism in the case of a center force location. If the force location is off-center, it is divided between the crank mechanisms according to the leverage ratio.

\subsection{Middle support}

Middle support is reducing the deflection of the shaft and bending stress. Because the center support is located in the center of the upper beam, this beam is deformed from this load in the same way. This support must not be considered as absolutely rigid in the crankshaft beam model (This would automatically lead to a statically undefined model). Considering the upper beam as a spring on the specified stiffness, a good quality beam model would be created.

As the upper beam stiffness is not known, the middle support is replaced by a lonely force in the shaft beam model (Fig. 3). The force representing the center bearing value is determined as a share of the nominal force and is optional for the beam model. [6], [7]

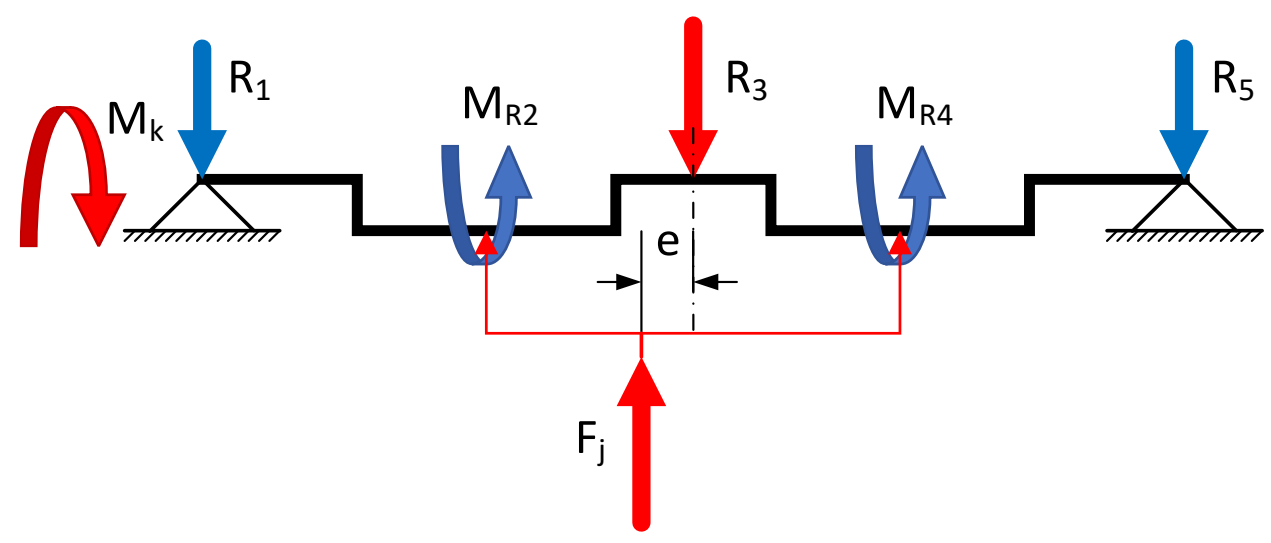

Fig. 3. Simple beam model of crankshaft with force replacing middle support 


\subsection{Simple beam supports}

The crankshaft is mounted in non-tilting plain bearings. The loaded shaft bents and distributes its deformation to the outer bearings, which leads to their tilting include the part of upper crossbar. The stiffness of the upper crossbar prevents the tilting of the bearings. In the simple beam model, it is necessary to choose between a free (rotation of the element is possible) or a fixed (rotation of the element is impossible) support. For further work, free supports are considered, because their application leads to higher stresses on the beam. This is advantageous with regard to the dimensioning of the crankshaft. The bearing pressure distribution is not constant because the bearing prevents shaft deflection (the bending moment is transmitted in the bearing). The triangular course of the bearing pressure across the bearing width is considered for further work. This leads to the possibility of determining support position for the beam model. In the case of a triangular course, it is located in $1 / 3$ of the bearing width.

\subsection{Torque distribution}

In case of a nominal force locating in the center of the press space, it can be assumed that half of the torque entering the shaft from the drive side is consumed by the first crank mechanism and the second half by the second crank mechanism. When the nominal force is off-center, it is assumed that the torque is divided between the crank mechanisms into the same ratio as for the nominal force.

\subsection{Stress components}

The magnitudes of the stress components in the individual cross sections for the derivation of the bending moment, torque and shifting forces are determined according to the principles of solid mechanics.

\begin{tabular}{|c|c|c|}
\hline Bending Stress & Shear Stress & Torsion Stress \\
\hline$\sigma_{o}=\frac{M_{o} c}{J_{z}}$ & $\tau_{s}=\frac{T}{S}$ & $\tau_{k}=\frac{M_{k} \cdot \frac{d}{2}}{J_{p}}$ \\
\hline $\begin{array}{l}M_{o} \ldots \text { Bending moment in extreme } \\
\text { locations } \\
J_{z} \ldots \text { Second area moment } \\
c \ldots \text { Distance from the neutral axis }\end{array}$ & $\begin{array}{l}T \ldots \text {. Shifting force in extreme } \\
\text { locations } \\
S \ldots \text { Cross section at extreme points }\end{array}$ & $\begin{array}{l}M_{k} \ldots \text { Torque in extreme locations } \\
J_{p} \ldots \text { Polar moment of Area } \\
\frac{d}{2} \ldots \text { Distance from the neutral axis }\end{array}$ \\
\hline \multicolumn{3}{|c|}{ Reduced stress (Guest method) } \\
\hline \multicolumn{2}{|c|}{$\sigma_{\text {red }}=\sqrt{\sigma_{o}^{2}+3 \cdot\left(\tau_{s}+\tau_{k}\right)^{2}}$} & (4) \\
\hline
\end{tabular}

Table 1. Components of combined stress [8]

\section{The simple beam model example for press $25 \mathrm{MN}$}

Specific calculations were made for a two-point press with a nominal force of $25 \mathrm{MN}$ whose basic parameters are as follows:

\begin{tabular}{|c|c|c|c|}
\hline Variable & Abbreviation & Value & Units \\
\hline Nominal force & $F_{j}$ & 25 & $M N$ \\
\hline Nominal torque & $M_{j}$ & 1,21 & $M N m$ \\
\hline Workspace width & $l_{w}$ & 1,3 & $m$ \\
\hline $\begin{array}{c}\text { Max. eccentricity of } \\
\text { the nominal force }\end{array}$ & $e$ & 0,45 & $m$ \\
\hline
\end{tabular}

Table 2. Basic parameters of $25 \mathrm{MN}$ press

The specific dimensions of the press are known, but are not presented for business secrets. The values of the stresses and the specific pressures are given because they are needed for mutual comparison. 


\subsection{Effect of the middle support}

The first question is: What is the influence of the middle bearing share (percentage of nominal force) on the transmission of the nominal force to the crankshaft strain? The centric load with nominal force is considered. In successive steps, the percentage of force in the middle bearing is increased.

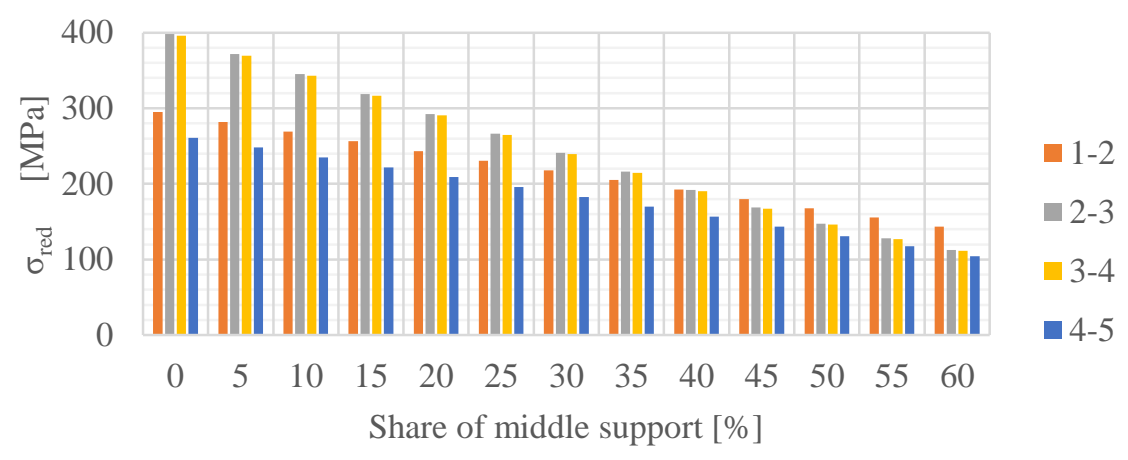

Fig. 4. Dependence of the share of the middle support on shaft stress at defined cross-sections of the crankshaft

The results show that crankshaft stress decreases as the share of middle support increases (Fig. 4.). This result was expected. The increasing load of middle support is mainly reflected in crankshaft bending stress reduction. Highest stress is on the torque input side of the shaft. In the case of a center load, $1 / 2$ torque is consumed on the first (left) crank mechanism and the second $1 / 2$ on the other.

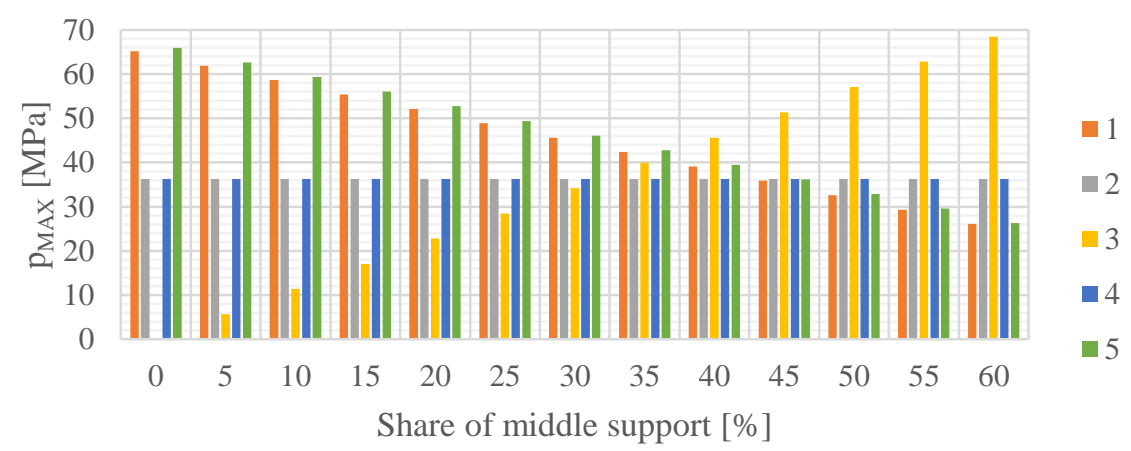

Fig. 5. Dependence of the share of the middle support on shafts' bearing pressure (Bearing positions: 1 - left; 2 - left con-rod; 3 - middle; 4 - right con-rod; 2 - right)

The pressures of the crankshaft bearings in the press stand are dependent on the increasing influence of the middle bearing. Without the middle bearing, the entire force is transmitted by the outer bearings and vice versa. The connecting rods bearings pressures are not dependent on the center bearing. The graph (Fig. 4) shows that the optimum load capacity of the middle bearing is approximately $35 \%$ (valid only for the bearing dimensions used).

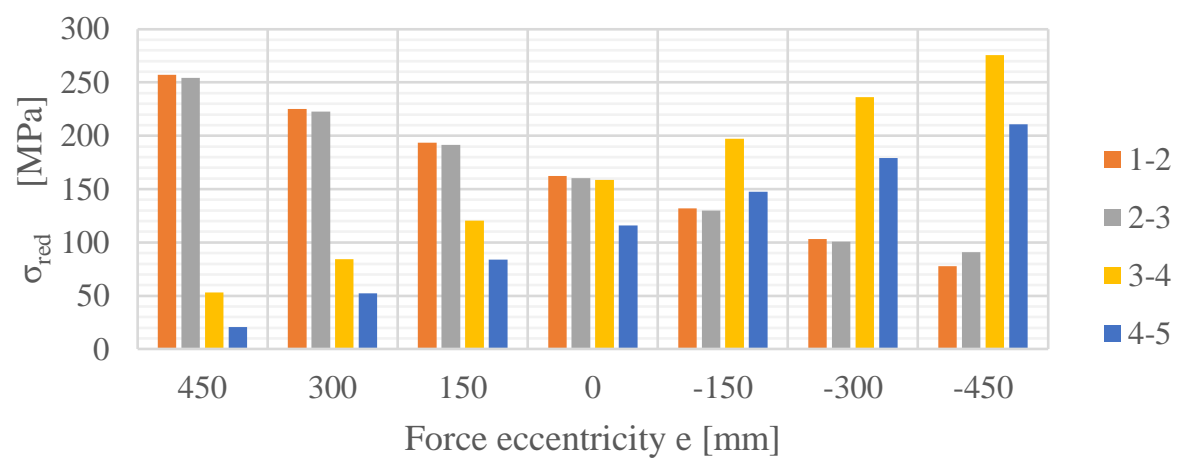

Fig. 6. Dependence of the share of eccentricity of nominal force on shaft stress at defined cross-sections of the crankshaft 
It is clear from the results that the optimum crankshaft load occurs in the case of a center load. Any out of center of the nominal force means increased crankshaft stress. The current trend of the same force load of all working positions is not optimal for crankshaft stresses.

\section{Virtual simulation for press $25 \mathrm{MN}$}

An example of a press used for a beam model was solved in a virtual simulation environment using FEM. The virtual simulation included the entire press (press stand, crank mechanism, ram ...). The simulation was solved using a contact simulation. The model was loaded with a nominal force located in the middle position (the force acts centrically) with a shaft rotated several degrees before the bottom dead center. Therefore, the shaft is mainly stressed by bending, shearing and minimally by torsion.

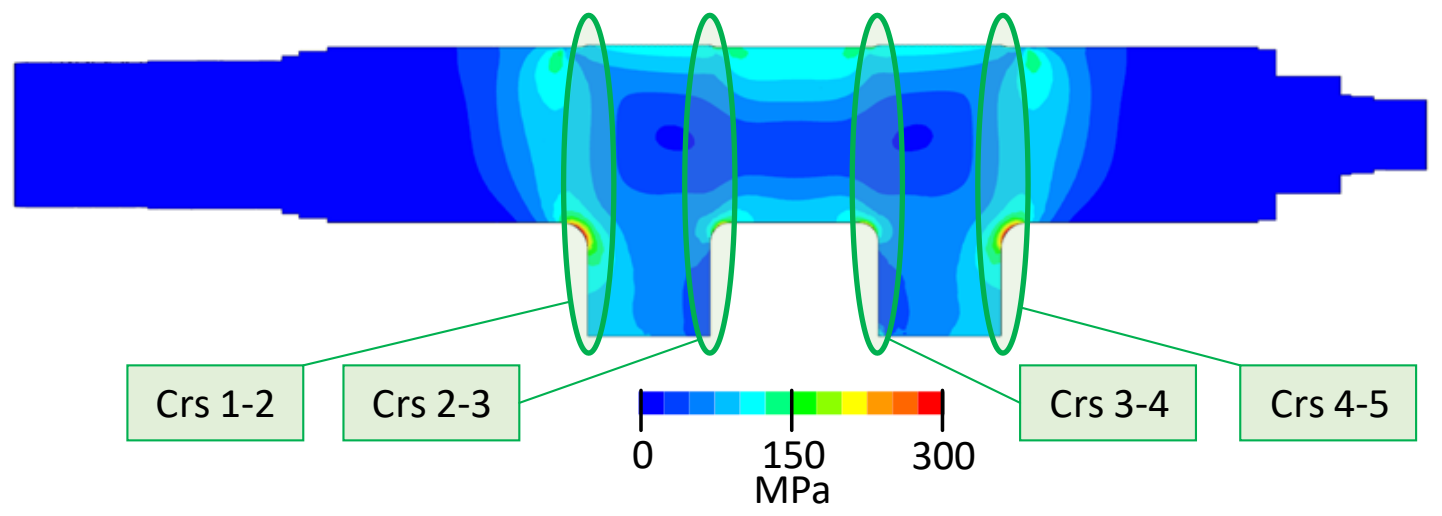

Fig. 7. Stress results (von Mises yield criterion) in sectional view of the crankshaft

The force transmitted by the middle support has a value of $6.63 \mathrm{MN}$ in the virtual model, which corresponds to $26.5 \%$ of the nominal force. The torque moment taken from boundary condition values is $55.8 \mathrm{kNm}$. These values are considered in the beam model used to compare the resulting crankshaft stress values.

\subsection{Bearing presses}

The outer bearing pressures of the crankshaft have been subtracted for finding a reaction force specific place. The position of this specific place will be used as the support position in the specified beam model. From the virtual model, the values of the contact force of the vertical direction in the individual nodes were subtracted. Subsequently, the specific place's position was calculated.
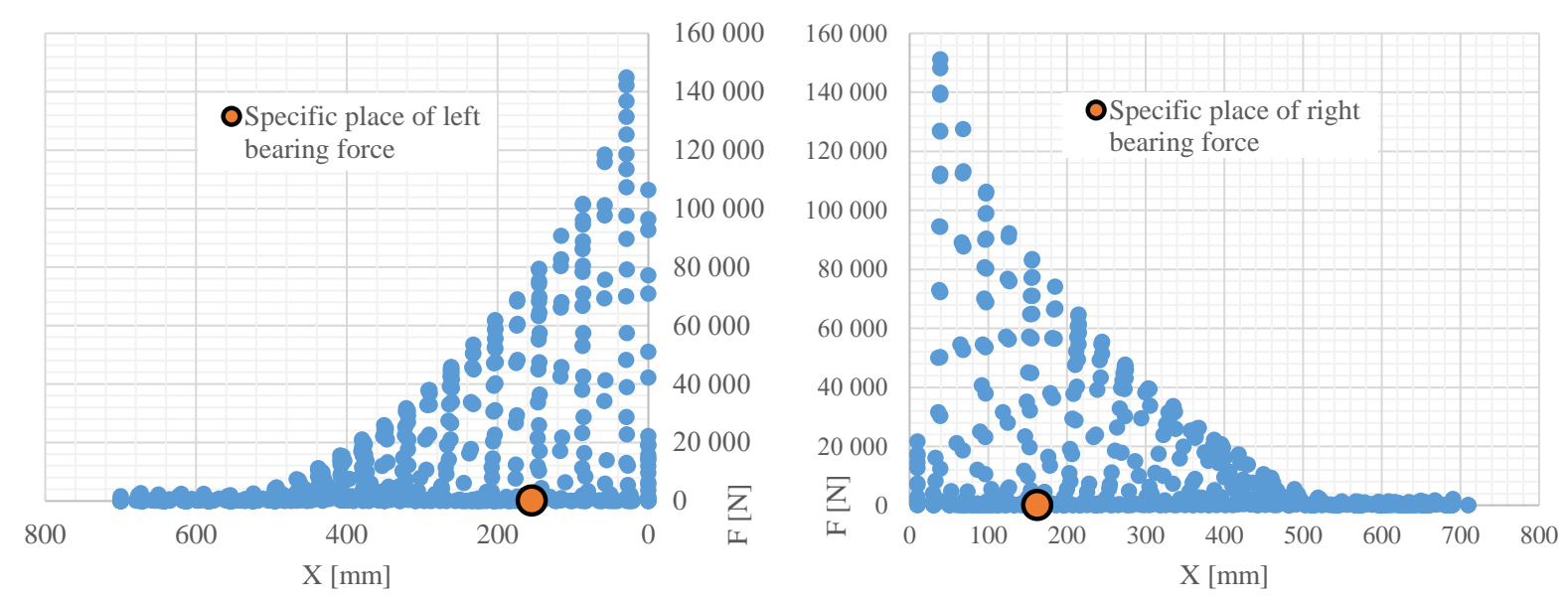

Fig. 8. Bearing forces in left and right crankshaft support

The specific places of the bearing forces were taken from the reading of the bearing forces of individual elements. These specific places have been used as a support positions for the beam model. The left bearing is $154 \mathrm{~mm}$ from the inner edge, and the right bearing is $162 \mathrm{~mm}$. 


\section{Comparison of stress results of simulations}

From a table comparing the results obtained in the simple beam model with the virtual simulation (Table 3 ), it is obvious that there was a mismatch.

The following considerations can be explained:

- The inability of the beam model to describe the behavior of the crankshaft at the point where the diameter changes.

- The simple beam model considers co-axial parts of the crankshaft, which does not correspond to the virtual model.

- The type of support (Simply supported) in the beam model does not correspond to the mounting condition in a plain non-tilting (rather) bearing.

\begin{tabular}{|c|c|c|c|}
\hline Cross section & $\begin{array}{c}\text { The simple beam } \\
\text { model }\end{array}$ & Virtual simulation & Units \\
\cline { 1 - 3 } Crs $1-2$ & 136 & 258 & \\
\cline { 1 - 3 } Crs 2-3 & 187 & 182 & \multirow{2}{*}{ MPa } \\
\cline { 1 - 3 } Crs 3-4 & 185 & 178 & \\
\hline Crs 4-5 & 131 & 251 & \\
\hline
\end{tabular}

Table 3. Comparison of results of used models of $25 \mathrm{MN}$ press

The mismatch also exists in the ratio of stress results. According to the simple beam model, higher values should be present on the internal tracking areas because the bending moment is higher there. The resulting virtual simulation strain values show opposite ratios. A possible explanation is the fact that a bending moment is also transmitted to the connecting rod bearings (the connecting rod bearing prevents the crankshaft from bending). The largest bending moment is accumulated in the outer cross sections (Crs 1-2 and Crs 4-5).

\section{Conclusion}

The aim of the present paper was to construct simple beam model of a forging press crankshaft, which would be used to design a new shaft. The crankshaft is one of the first components to design. Another goal was to use the results for crankshaft design with regard to durability. Verification of the correctness of the simple beam model results was realized using a virtual model using FEM. The virtual model consisted of a complete crank press. Its credibility is very high. A comparison of the results of the simple beam model and the virtual simulation revealed a disagreement.

The stress results of the virtual model are significantly higher. Probably due to the impossibility of a simple beam model to describe realistically the behavior of the crankshaft at the points of significant cross-sectional variations. A more serious mismatch is the mismatch in the ratio of stress values. The simple beam model assumes higher stresses in internal cross-sections. In a virtual model, however, higher values occur on external cross-sections. An explanation may be the fact that the connection rod bearings (or the whole connecting rod) limits the crankshaft in its deflection.

The result is thus insufficient. It can be assumed that, after performing proposed further actions, the accuracy of the simple beam model will be increased.

\subsection{Future steps}

To achieve a functional simple beam model, it is recommended to perform the following steps:

- To subtract the resistive bending moment of outer bearings and to parameterize its insertion into the simple beam model.

- To subtract the resistive bending moment of connecting rod bearings and to parameterize its insertion into the simple beam model.

- To subtract the bearing pressure of the connecting rods bearings and to parameterize the adjustment of the specific places of forces from the connecting rods.

- To expand calculation of the crankshaft simple beam model for crankshaft durability analysis.

\section{Acknowledgments}

This article was done by financial support SGS-2016-012 of University of West Bohemia. 


\section{References}

[1] Chval, Z. \& Čechura, M. (2017). Mechanical Forging Press for Progressive Working in Automatic Process, Proceedings of the 28th DAAAM International Symposium, pp.0367-0371, B. Katalinic (Ed.), Published by DAAAM International, ISBN 978-3-902734-11-2, ISSN 1726-9679, Vienna, Austria DOI: 10.2507/28th.daaam.proceedings.051

[2] Qi, Z., Peng, J., Xueping, R. (2014). Forging Force Analysis of Truck Knuckle and Selection of Forging Equipment, Procedia Engineering, Volume 81, 2014, Pages 450-455, ISSN 1877-7058, https://doi.org/10.1016/j.proeng.2014.10.021

[3] Chval, Z. \& Cechura, M. (2016). Design of mechanical forging press with maximal force in side cavity. MM Science Journal, 2016, November, p. 1358-1361. ISSN: 1803-1269

[4] Chval, Z. \& Čechura, M. (2014). Monitoring Extremely Stressed Points on Stands of Forging Presses, Procedia Engineering, Volume 100, 2015, Pages 841-846, ISSN 1877-7058, https://doi.org/10.1016/j.proeng.2015.01.439.

[5] https://en.wikipedia.org/wiki/Beam_(structure), 2018. Wikipedia.org, Accessed on: 2018-03-13

[6] Baragetti, S. (2015). A Theoretical Method for Structural Design and Analysis of Crankshafts, Int. J. Vehicle Structures \& Systems, 7(3), 92-99. ISSN 0975-3060. doi:10.4273/ijvss.7.3.02

[7] Baragetti, S. (2015). Design Criteria for High Power Engines Crankshaftss, Int. The Open Mechanical Engineering Journal, 2015, 9, 271-281, ISSN: 1874-155X, DOI: 10.2174/1874155X01509010271

[8] https://www.kme.zcu.cz/kmet/pp/. Department of Mechanics/Faculty of Applied Science/University of West University, Tension and strength hypothesis (Napjatost a hypotézy pevnosti), Accessed on: 2018-03-13 